Ant Addresz or

\section{ENCEPHALTTIS LETHARGICA.}

\section{Given to the South Midland Branch of the British} Medical Association

BY

\section{M. HINDS HOWELL, M.D., F.R.C.P.,}

ASSISTANT PHYSICIAN, ST. BARTHOLOMEW'S HOSPITAL, LONDON.

In the spring of 1918 a series of cases appeared in this country which presented certain novel features. Professor Arthur Hall and Dr. Wilfred Harris independently drew attention to this occurrence in adults, whilst the late Dr. F. E. Batten pulslished an account, under the title of " Epidemic stupor in children," of a series of cases which had been under his observation at the Hospital for Sick Children, Great Ormond Street, London. The suggestion was made tentatively that the cases might possibly be examples of botulism, with which they had some features in commonnamely, ocular palsies, drowsiness, muscular weakness, and sphincter troubles. The food supplies at that time were not of the best, but it soon became obvious that the cases, which were appearing in increasing numbers, had nothing to do with $B$. botulinus, but were evidence of a widespread epidemic. Attention had already been called to its occurrence in 1917 by von Economo in Austria and by Netter in Paris.

Since that date we have had the disease constantly with us. In January, 1919, notification was made compulsory by the Local Government Board. The number of cases notified since then has been: 541 in 1919, 890 in 1920, 1,470 in 1921, 454 in 1922, and 1,123 in 1923 . So far as I can judge, the figures for 1924 are likely to be as high as those for 1823, or even higher. It is, of course, probable that all cases of the disease are not notified, as many atypical cases occur in which the diagnosis is likely to be missed.

\section{Etiology.}

Certain facts have been brought out as the result of notification. The incidence of the disease is highest in the winter months January, February, and March; in this respect it offers a striking contrast with the seasonal incidence of poliomyelitis-a matter of some importance when considering the etiological relationship of these two diseases.

The age incidence is fairly evenly distributed. The disease may occur in babies or septuagenarians. In this respect also it offers a striking contrast with poliomrelitis, as in the latter 80 per cent. of the cases occur under the age of 20 . The disease is contagious to only a very slight degree; in my own experience I have not come across more than one case in any one family, nor have $I$ any experience of infection occurring in hospital, either among patients or nurses, in a ward in which cases of encephalitis were being cared for. In this respect the disease resembles poliomvelitis and meningococcal meningitis. But cases are on record of direct spread by contagion, though their numbers are few. In 1919 I had under my care a woman with a typical attack of encephalitis lethargica who was nursing a kaby a few weeks old, and who had done so for at least a fortnight. The mother's attack was very severe, but the baby escaped infection. Hall, in his monograph, quotes a similar case in which the child became infected and died, and another which shows perhaps that there is a possibility of infection being carried through the mother's milk. In this case a pregnant woman developed the disease two weeks before her child was born. The child was at birth quite healthy, lively, and active. After being put to the breast it gradually developed torpor and somnolence. It was weaned, and almost immediately recovered and remained well.

The actual infecting organism has not been satisfactorily identified. From von Economo's cases von Weisner recovered a streptococcus growing in pairs, and in one of two monkeys he reproduced certain symptoms of the disease -lethargy, dysphagia, and paralysis-but subsequent investigations have failed to confirm these findings.

In 1919 and 1920 Strauss, Hirschfeld, and Loewe succeerled in reproducing the disease in a monkey (Macacus rhesus), and in rabbits, by using emulsion of brain from cases of encephalitis lethargica. They were also successful with washings from the nasopharynx of living patients. They isolated a virus from this material which proved to be a filter-passer, and also to be capable of preservation in glycerin. In these respects it closely resembles the virus of poliomyelitis.

It is probable that in both these diseases. as also in meningococcal meningitis, the infecting agent gains access to the central nervous system through the nasal mucosa, and that in all of them "carriers" exist. The separation of a virus from cases of herpes labialis, which experimentally reproduces many of the symptoms of encephalitis lethargica, is a matter of great interest, but does not lessen -indeed, it rather increases-the difficulties. This virus also is a filter-passer and can be preserved in glycerin

Levaditi and his co-workers conclude that encephalitis lethargica is due to a specific virus with the characteristic: already referred to, and that it exists in an attenuated form in the saliva of healthy persons, in a more virulent form in the vesicles of herpes labialis, and in its most virulent form in the saliva of carriers, and in the nasopharyngeal mucosa and nervous tissues of persons suffering with encephalitis. These results have not been universally confirmed, Flexner and others having failed to get any positive results with inoculations from cases of encephalitis.

At this point I must say something about the possible relationship of encephalitis lethargica with influenza. Experience of the last few years has shown that outbreaks of the two diseases are apt to occur simultaneously. Further, a review of past influenza epidemics reveals the fact that cases presenting a clinical picture very similar to that of encephalitis lethargica occurred at these times. It seems clearly established that epidemiologically there is a close connexion between influenza and a group of diseases affecting the nervous system, of which encephalitis lethargica, cerebro-spinal fever, and poliomyelitis are members. The suggestion was made in the early days of the encephalitis epidemic that it might be a cerebral form of influenza. If such were the case we should expect to find cases of encephalitis lethargica and influenza occurring in the same household, as no disease is more highly contagious than the latter. This relationship, however, is far from existing. Moieover, we have seen that encephalitis lethargica appears only exceptionally to be contagious to any marked degree. We must leave it to the future to determine to what extent these diseases are mutually related.

Epidemic hiccup has occurred in various outbreaks since the appearance of encephalitis lethargica, and the question has arisen whether it may not be a manifestation of the latter disease. There is no positive evidence that it is, and some evidence to show that it is not; persistent hiccup is not a common symptom in definite cases of encephalitis lethargica, and cases of hiccup do not as a rule exhibit other symptoms suggestive of encephalitis. Recently, however, I had under my care a medical man with epidemic hiccup, who also had definite evidence of an encephalitis, as the result of which he developed hemianopia. Epidemic hiccup would appear to be more definitely contagious than is encephalitis lethargica.

\section{Srmptoms.}

We are dealing with an infection which produces tissue reactions scattered at random throughout the whole nervous system; the main incidence is now in one place, now in another. The clinical picture will be determined by the extent of the damage done to the several parts of the nervous system involved. Meninges, cortex, centrum ovale, basal ganglia, mid-brain, pons, medulla, spinal cord, and even at times peripheral nerves, may each and all of them hecome involved. It is true that the chief focus of the disease is apt to be in certain localities more than others, the mid-brain and basal ganglia perhaps especially; the result is that what has been described as the oculo-lethargic trpe recalls the clinical picture that we all should regard as probably most characteristic of the disease. It is indeed a picture which is rarely produced by other conditions, and in its most typical form by none. To multiply types of this disease by naming some dozen or more syndromes by their most striking features serves no useful purpose. 
The onset of the disease may be acute and dramatic in the suddenness and severity of the symptoms produced, or it may be very insidious. In my experience the oculo-lethargic group of cases are likely to belong to the latter category. 1 have seen a number of such cases, referred to me on account of a diplopia of doubtîul origin, and complaining of little else. 'The initial period in these insidious cases may be prolonged, constituting what may be regarded as a prodromal period in which the chief symptoms are lassitude, somnolence, slight headache, depression, and irritability. When the disease enters on a more active stage, and in cases of sudden and acute onset, fever is, I think, alwavs present. Its duration may be a matter of hours, or it may be present for weeks, but the febrile period is as a rulo short: I have had two cases under my care in which the patient was febrile for a period of eight weeks. One of these patients recovered. Cases in which the febrile period has lasted for months are on record, but these are fortunately quite exceptional. Although commonly of low grade, high degrees of fever, sometimes even hyperpyrexia, may occur. The latter is usually, but not alwass, a terminal event. A steadily rising temperature at the end of a prolonged period of pyrexia is an ominous sign. The tongue is heavily furred, of ten greenish or brownish-white, the breath foul, and the bowels usually severely constipated. Abdominal pain, associated sometimes with vomiting, may occur. I have recently seen a case which was admitted to hospital as appendicitis.

There is nothing remarkable in the condition of the pulse, nor in the lungs, but there may be peculiarities in respiratory rhythm during the active stage of the disease. Polypnoea with periods of apnoea has been observed on several occasions, due almost certainly to disturbance in connexion with the respiratory centre in the medulla. Drowsiness is one of the striking features of the disease, both in its active stage and as a sequel. It is often one of the earliest symptoms.

I saw in May, 1924, a man of 60, who gave the following history. $\mathrm{He}$ had started the year with an attack of influenza, which left him with sciatic pain, for which he took salt baths at Southend. In the middle of April he had his usual bath and then sat down on a seat on the parade. Here he found that he had diplopia, felt sleepy, and complained of slight headache. He travelled to lelt sleepy, and complained of slight headache. He travelled to he went to sleep in the road, lying down against a tree. He was awakened by a policeman, who suggested he should go home to bed, and evidently thought that my patient had been drinking. started for home, but was overcome with sleep a second time. reached his home about 4 a.m. Normally he should have got there in fifteen minutes from the station.

Another patient-a man of about 40 -was playing in a two-day cricket match. On the evening of the first day he noticed that he saw double at a cinema performance. He put this down to the heated atmosphere and went home to bed. He played cricket all next day with success, and with no visual troubles. He started to ride home on a motor bicycle about 5 p.m. to go perhaps thirty or forty miles. He has no recollection of anything after that till 4 o'clock the next morning, when he found he had been asleep by the side of the road about a mile from home. He was able to waken his chauffeur, who lived close by, and was assisted home by him.

The condition of drowsiness frequently advances to one of seemingly profound lethargy; it is remarkable how a patient in such a condition can be roused to answer a question intelligently, but at once relapses again. The lethargic periods of ten show remarkable remissions. A boy under my care would be profoundly lethargic during the morning, going to sleep whilst the nurse was endeavouring to give him food, but in the afternoon would become quite wide awake and alert, and demand comic papers.

With this pronounced lethargy the patient may frequently suffer from insomnia. This may simply be inahility to sleep at night, but is sometimes accompanied by nccturnal excitement. A girl in St. Bartholomew's Hospital was profoundly lethargic by day, but at night became extremely excited, sang songs at the top of her voice, wanted to jump out of hed, and threw anything left within her reach at any nurse who happened to be near. Mental symptoms are frequently observed; the mildest is a lack of restraint comparable in many respects to the mental condition of one not drunk, but " having drink taken." A young man recently under my care suffering from diplopia, slight fever, and a moderate degree of drowsiness, insisted on explaining at great length how badly he had treated a girl to whom he had been engaged, by breaking off the engagement in a most incon- siderate manner. In his normal mental condition he is a very reservel personality. Delirium of a "busy" kind is common. I have heard patients carrying on imaginary conversations on the telephone, dictating letters, smoking imaginary cigarettes, and so on. Sometimes, though I think only occasionally, a patient becomes maniacal.

One very striking case of the kind occurred in a patient under my care in 1918. He remained more or less comatose for about six weeks, and then became maniacal. Arrangements had just been completed for his removal to more suitable surroundings when the attack of mania ended as suddenly as it had begun, and he became quite normal, all tracc of lethargy passing away at the same.time as the mania.

Among symptoms due to lesions in the nervous system ocular phenomena take first place. Any or all of the oculomotor nerves may be involved, the paralysis usually being of the nuclear type with conjugate movements affected. Ptosis is extremely common, and helps to add to the appearance of somnolence which is so characteristic. The pupils show a variety of changes-small, dilated, unequal, the Argyll Robertson type, failure to react to light or accommodation. Much interest attaches to the condition of the optic disc. Papilloedema, which at one time was thought never to occur, is now recognized as being present occasionally; usually it is of low grade with but little swelling; haemorrhages are rarely met with. An intense papilloedema with much swelling and haemorrhage makes the diagnosis of encephalitis lethargica extremely doubtful.

I recently saw a patient who was suffering from intense headache, was drowsy at times, had a nuclear paralysis of the third nerves with loss of upward movement of the eyes. At this was sudden in its onset and the patient was thought to be suffering from encephalitis lethargica. Examination of the disc revealed the presence of an intense papilloedema with haemorrhages. A diagnosis of mid-brain tumour was accordingly made, and verified, unfortunately, at a subsequent autopsy.

Other cranial nerves may be affected, the commonest in my experience being the seventh. I have never seen examples of paralysis of the fifth or twelfth nerve, though it has been ohserved. The patient may quite early exhibit the Parkinson facies, with characteristic attitude of the arms and hands, rigidity, and, less commonly, tremor. Where these symptoms occur early I have thought the prognosis, even as regards life, to be grave and that the Parkinsonian scquel was assured in the event of the patient surviving. This view may, however, prove quite erroneous.

$A$ girl of 17 was admitted under my care at the National Hospital in the early and acute stage of the disease. She had already developed a very severe degree of the Parkinson syndrome already developed a very severe degree of the Parkinson syndrome mouth, and incontinent. I gave an extremely bad prognosis as regards recovery, and said that if she did recover she would be a hopeless case of paralysis agitans. Both predictions happily were entirely wrong. She made a complete and uneventful recovery, and is at present a member of a theatrical company, and very successful, I understand, as a dancer.

Buzzard and Greenfield first drew attention to the occurrence of hemiplegia as a symptom of encephalitis lethargica, and many such cases have since been observed.' There is, of course, nothing characteristic in the hemiplegia itself, and often the diagnosis can only be made by a careful consideration of the circumstances in which the condition developed, and by a reasoned process of exclusion. Katatonia has been present in a large number of cases, and when present may be an important aid to diagnosis. Considerable interest also attaches to a number of other motor. disorders of an irritative character. Among them must he mentioned fits, choreic movements (of which many cases appear to have occurred in the recent outbreak), a more pronounced type of involuntary movement designated under the title of choreo-athetoid movements, myoclonus, and muscular spasm. Epileptic attacks may occur as an initial symptom, during the course of the disease, or as an after-effect; they are more likely to occur in those cases in which the cortex is most involved, and in such cases present the common picture of clonic convulsions; but in cases where the mid-brain is chiefly involved "tonic fits" may occur, associated with rigidity and extension of the limbs. Fits, however, are not a common symptom in the disease. Involuntary muscular movements are more frequently met with. Two cases were admitted recently to St. Bartholomew's Hospital as chorea, but in the wards the nature of the cases became clear. C'ases of choreo-athetosis are much less common. I have seen only one of the kind; it was 
treated in the National Hospital. The movements and gesticulations exhibited were of a particularly striking character, though they did not develop until eighteen months after the initial illness.

Myoclonus occurs in a fair number of cases; the muscular contractions may involve the whole or part only of any particular muscle, sometimes causing movement of a limb and sometimes not. The muscular contractions are usually painless, but severe cramp-like pain may be experienced, and this, I think, more particularly when the abdominal muscles are involved. Muscular spasm sometimes persists for a long period, and I have seen one patient with a residual torticollis, which still persists. Peripheral nerve palsies rarely occur. I have seen two or three such cases in which the external popliteal nerve was affected, with resulting foot-drop; and another remarkable case in a boy of generalized weakness with moderate muscular wasting and absence of reflexes which suggested widespread peripheral neuritis.

Pain, apart from muscular spasm, has been noted in a number of cases. I have already referred to the case of a boy who was admitted to hospital with abdominal pain and vomiting as the result of which he had been diagnosed as a case of appendicitis. In other cases the diagnosis of rheumatic fever has been made. I have seen two such cases recently. It is interesting to note that a similar mistake is sometimes made in connexion with poliomyelitis.

\section{SequelaE.}

I must now briefly refer to the sequelae. With regard to these it may at once be said that the diagnosis of encephalitis lethargica is in many cases more easily made in the presence of its consequences than during the initial attack.

One of the most striking sequels is paralysis agitans. have referred already to the early appearance of Parkinson symptoms; they may entirely disappear, or pass into a chronic and persisting residual condition. On the other hand, cases in which the patient appears to have made a good recovery may begin many months later to develop the characteristic symptoms of paralysis agitans. Its features resemble very closely those of the ordinary senilo type-facial immobility, weakness and rigidity of the limbs, the flexed attitude, the gait, are all present. Tremor is the symptom which is most likely to differ, in that it is not, in my experience, either so common, or when present so constant, as in the senile form. It may have a partial distribution, usually hemiplegic. I have several patients who show this well.

Residual ocular paralysis is common-che degree very variable. When all other movements have returned it is not uncommon to find that convergence is still faulty. Mental changes are also unfortunately very common. The bright child becomes dull, the " easy" child " difficult." Depression, sometimes amounting to melancholia, is not uncommon, and easily to be understood, in the cases with the Parkinson syndrome. More than one of my patients has stated, "I have forgotten how to laugh"; in some all emotional response has disappeared.

Impulsive tendencies are noticeable in a few cases; one of my patients always felt the strongest impulse to get in front of express trains, or if water were rushing under a bridge to jump into it, though she had no wish to commit suicide. She presented Parkinson symptoms, and the rapid movement made an almost irresistible appeal to her. A certain number of cases drift into asylums, but fewer than might be expected. Disorders of sleep may persist long after the acute stage of the disease is over-somnolent by day, the patients may awake to an excited activity at night. $I$ do not know the meaning of this inversion, but its presence I have noted many times.

Involuntary movements, spasms, and tics of various kinds are not uncommon; several cases of the latter $I$ have seen in connexion with the respiratory movements. Residual paralysis in the form of monoplegia or hemiplegia is met with in those cases in which it has been present during the initial stages. It does not tend to develop after apparent recovery in the same way as paralysis agitans commonly does. Seborrhoea of the scalp and forehead, sometimes to a most striking degree, may be noted. Lastly, obesity, possibly as the result of some disordered function of the pituitary, has occurred in a number of cases.

This list does not pretend to be in any way comprehensive, and I have no doubt that other sequelae have been observed. I have stated here those which in my own experience have proved most likely to occur.

I must not leave this aspect of the disease without making some reference to relapse. This occurs in an acute form in a number of cases. It is uncertain at what period we can regard a patient who has suffered from the disease as free from danger of relapse or the development of the dreaderl Parkinson syndrome. I have observed what I thought was relapse in a case of this kind exactly two years after the original attack. The very long interval made me somewhat doubtful of the correctness of the original diagnosis, but reports of similar intervals, though unusual, have been made.

\section{Pathology.}

Macroscopically there is very little to see in these cases. Occasionally there are meningeal haemorrhages, usually quite small, but sometimes moderately extensive. The meninges may have a milky appearance if the superficial cellular exudate has been considerable. The brain on section is softer than normal, and numerous punctate haemorrhages are visible. These haemorrhagic points are probably the most constant macroscopic finding.

Microscopically the most striking and obvious appearances are furnished by a perivascular collection of small round cells which fill the Virchow-Robin space and form a cuff to the blood vessels. The cells in this exudate are for the most part lymphocytes, but plasma cells are also to be found. The exudate may be seen in connexion with capillaries, veins, and arterioles. The majority of observers regard this as a cellular exudate, though Buzzard and Greenfield are of the opinion that the cells are entering and not leaving the blood vessels.

There is for the most part no cellular reaction in connexion with the vessel wall, but a remarkable occurrence is calcareous arterial degeneration, which has been frequently observed. This is chietly to be found in the vessels of the anterior part of the globus pallidus of the lenticular nucleus; it is sometimes accompanied by thrombosis of the affected vessel. It is remarkable how early this calcareous degeneration may occur. Far from being a late change in the neighbourhood of an inflammatory focus, calcification has been noted as early as the seventh day of the disease. Collections of cells are also met with, apart from the vessels, in the tissues. The vascular changes and cellular foci here referred to may occur throughout the whole of the nervous system, not excluding the spinal cord. The pains, myoclonus, and muscular spasms that occur as clinical manifestations of the disease no doubt owe their existence to these scattered lesions.

Changes in the nerve cells are met with, similar in character but much less extensive than are found in poliomyelitis. The changes consist of (1) neuronophagia, in which the nerve cell appears to be undergoing a destructive change as the result of the activities of proliferated neuroglial satellite cells; (2) chromatolysis, with swelling of the nerve cell, eccentricity of its nucleus, and diffuse staining of Nissl granules; (3) neuroglial proliferation. In cases of the Parkinsonian type many observers have described profound degenerative changes in the cells of the substantia nigra in the mid-brain. This has opened up a wide field for further investigation which is likely to throw light on the physiological functions of the cells of the substantia nigra. In addition to these changes, fatty globules, which tend to become agglomerated and to undergo calcareous deposition, have been observed in many cases.

Contrary to what might have been expected, the cerebrospinal fluid usually shows few changes from normal. But changes may be met with in connexion with the cells and the protein and sugar content. Although the count of cells is usually lower than 10 cells per cubic millimetre, there may be a considerable increase-counts of 30 to 80 cells per cubic millimetre are met with occasionally. It is very rare to find more than 100 cells, and if such a number are present it suggests meningitis as opposed to encephalitis lethargica. These cells are almost entirely lymphocytes, 
In which respect this disease resembles poliomyelitis, and incidentally tuberculous meningitis-a disease which often causes a good deal of difficulty in diagnosis.

The protein content of the cerebro-spinal fluid rarely shows any marked increase, whilst the reverse is the case in meningitis, but 0.03 per cent. is sometimes met with. The chlorides are not altered-another point which in a doubtful case may prove of use in making a diagnosis of encephalitis as against meningitis. In the latter the chlorides constantly show a small reduction. Any figure below 0.68 per cent. would suggest meningitis very strongly. So, too, with the glucose content. In encephalitis this is unaltered, or even slightly increased, whilst in cases of meningitis, and more particularly tuberculous meningitis, the quantity is substantially diminished or absent. Changes in the blood are not striking-a small leucocytosis with a total count of 10,000 to 12,000 may be expected.

\section{Differential Diagnosis.}

Encephalitis may be extremely easy or impossible to diagnose. Often it is much easier to recognize from its sequels than during the initial stages. Whilst it is true that in many cases the disease has escaped recognition, it is no doubt also true that in the interest aroused by the advent of a new disorder-at any rate new within our experience-many cases have been labelled encephalitis lethargica which were nothing of the kind. Of acute infections, those most likely to cause trouble in diagnosis are influenza and tuberculous meningitis. The former suggests encephalitis in those cases in which headache, prostration, drowsiness, and fever are the prominent symptoms, whilst the latter may exactly reproduce the clinical picture of encephalitis.

The absence of such signs as retraction of the abdomen, rigidity of the neck, Kernig's sign, and tache cérébrale should help in the diagnosis, though the intrinsic value of each as a diagnostic sign is slight. A careful comparison of the cerebro-spinal fluid in conjunction with the clinical picture should help materially in the recognition of tuberculous meningitis and make the diagnosis certain if other forms of meningeal inflammation are present.

I have already referred to possible difficulties in connexion with chorea, and to errors which occasionally arise in connexion with abdominal pain and rigidity. Vascular lesions may cause great difficulty, and I think that in connexion with these the diagnosis of encephalitis is more likely to be made in error than the converse. The age of the individual is no help in this connexion, as we have seen that encephalitis has no regard to age. Tumour or abscess of the brain sometimes suggests encephalitis, bnt the presence of papilloedema of a marked type would be much in favour of tumour, although we have seen that a low-grade papilloedema sometimes occurs in encephalitis. The absence of any probable cause for abscess should help in its exclusion, but the presence of an ear discharge, present or recent, does not exclude the possibility of encephalitis.

\section{Prognosis.}

Even more difficult than diagnosis is prognosis. Two points have to be considered: will the patient recover, and, if so, will recovery be complete? or will one or other of the sequelae arise? The answer to the first question may remain long in doubt. No definite answer can possibly be given to the second.

Severity of onset does not necessarily imply a fatal issue, nor should too optimistic a view be taken with regard to a case of insidious and apparently mild onset. It would be possible to quote many cases to illustrate the truth of this. Cases with a prolonged febrile period are, I am sure, dangerous. I have referred already to the ominous significance of a slowly rising temperature after a febrile period of two or three weeks. Statistics of the mortality of the disease have varied from 30 to 50 per cent.-figures which are, of course, quite useless in helping to make a prognosis in any individual case.

With regard to sequelae, one can say that of the cases which recover perhaps 50 per cent. will have residual symptoms, from some of which, notably the Parkinson syndrome, they may die. Many of these sequelae no doubt will be slight, and not in themselves disabling. It is inportant to remember that a case which has made an apparently perfect recovery may develop some sequel at any time in the next two years. After that period I should say the risk was negligible, and the majority of patients show evidence of incomplete recovery within twelve months.

\section{TreatMent.}

There is unfortunately no specific treatment that has proved its value. I an convinced of the importance of recognizing the early ambulatory type of the disease and putting the patient to bed. There treatment on general lines must be carried out in so far as diet and regulation of the bowels are concerned. Most of the patients suffer with obstinate constipation.

A gargle of potassium permanganate may well be used by the patient, if he is in a condition to so do-and by those in contact with him.

With regard to any special therapeutic measures, it is safe to say that none has so far offered convincing evidence of success. Hexamine has had an extended trial, by tho mouth, hypodermically, and intravenously, but the results have been disappointing. In some cases serum, either from the patient, or simple horse serum, and in some cases antimeningococcal serum, has been used apparently with advantage. Repeated lumbar puncture has been recommended, although it is difficult to see on what logical grounds; I have, however, seen an improvement in the depth of the lethargy follow a lumbar puncture. Insommia, delirium, or excitement can be dealt with on ordinary lines. The residual symptoms or sequelae are extraordinarily resistant to every therapeutic measure.

\section{THE ANTE-NATAL CLINIC.* BY \\ GUY BELLINGHAM SMITH, M.B., F.R.C.S., SENIOR OBSTETRIC SURGEON, GUY'S HOSPITAL.}

I Have chosen the subject of the ante-natal centre, not because $I$ am the best fitted to deal with it, but as an act of atonement for a certain lack of faith in the first instance. Those of you who, like myself, have worked for rears amongst the very poor know how, with their poverty, goes a certain pride, which resents interference in their affairs. I thought of the difficulties we should have in getting the confidence of these people, and $I$. was unable to anticipate the results that have followed the working out of the scheme. I was reckoning without the enthusiasm and tact that sisters and health visitors have brought to the work, and the enthusiasm again and knowledge that those responsible for the medical side have shown.

I am surprised sometimes at reading the statistical results of fifty years ago, and we occasionally come across to-day despondent remarks as to the progress made in midwifery. These are mainly based on mortality results, and more particularly on those relating to puerperal fever. I have no doubts as to the progress made, having watched the results over a period of forty years. To begin with, figures are not always reliable, and we nust remember further that the range of work dealt with to-day is enormously greater than it was at that time, and that mortality results are more accurately stated. When we remember that our armamentarium consisted of a bottle of ergot, often administered too soon, and a Higginson syringe, which was used indiscriminately for the rectum and the aterus, we may wonder that the results were so good as they were.

But, however we may argue about death rates, who can doubt the enormous improvement that has taken place in the morbidity results? Where are the cases of vesicovaginal fistula that were a commonplace in the operating theatre of a few years past? Where are the sequels of severe injuries and sloughing of the vaginal passage, the atresias, the entire loss of the urethra or of the posterior bladder wall? I never see them to-day.

During the last year or two there has been a complete revolution in the hospital practice of midwifery. For many

* The Purvis Oration, delivered before the West Kent Sedico-Chirurgical Society, December 12th, 1924 . 